\title{
BMJ Open Perinatal consequences of a category 1 caesarean section at term
}

To cite: Grace L, Greer RM, Kumar S. Perinatal consequences of a category 1 caesarean section at term. BMJ Open 2015;5:e007248. doi:10.1136/bmjopen-2014007248

- Prepublication history for this paper is available online. To view these files please visit the journal online (http://dx.doi.org/10.1136/ bmjopen-2014-007248).

Received 19 November 2014 Revised 30 June 2015 Accepted 2 July 2015

CrossMark

\begin{abstract}
${ }^{1}$ Mater Mothers' Hospital, South Brisbane, Queensland, Australia

${ }^{2}$ Mater Research InstituteUniversity of Queensland, South Brisbane, Queensland, Australia
\end{abstract}

\section{Correspondence to} Professor Sailesh Kumar; sailesh.kumar@mater.uq.edu. au

\section{ABSTRACT}

Objective: To characterise maternal demographics, obstetric risk factors and neonatal outcomes associated with term category 1 caesarean sections (CS).

\section{Design and setting and main outcome} measures: Retrospective study of term singleton pregnancies delivering at a major tertiary unit in Brisbane, Australia. Category $1 \mathrm{CS}$ were defined as one that required a decision-to-delivery time interval of $<30$ min when there was an immediate threat to the life of a woman or fetus. Neonatal outcomes analysed were gestation at delivery, birth weight, Apgar scores, acidosis at birth, need for resuscitation, admission to neonatal intensive care and neonatal seizures and death.

Results: A total of 30719 women delivering at term were included. Of these, 1179 (3.8\%) women required a category $1 \mathrm{CS}$. A further 3527 women underwent non-category $1 \mathrm{CS}$. Most category $1 \mathrm{CS}$ were performed for non-reassuring fetal status $(65.9 \%, 777 /$ 1179). The indications for non-category $1 \mathrm{CS}$ were for failure to progress $(46.5 \%, 1641 / 3527)$ and nonreassuring fetal status (19\%,671/3527). Maternal age, body mass index and medical disease did not differ significantly between the two cohorts. Caucasian women were equally as likely to undergo a category 1 CS as a non-category $1 \mathrm{CS}$, while indigenous women and women of Asian ethnicity were more likely to undergo a category $1 \mathrm{CS}$. Significantly higher $(p<0.001)$ perinatal complications were seen in the category 1 CS cohort-Apgar scores $<7$ at $1 \mathrm{~min}$ $(20.4 \%, 241 / 1179$ vs $10.7 \%, 377 / 3527)$ and $5 \mathrm{~min}$ $(5.8 \%, 68 / 1179$ vs $1.9 \%, 67 / 3527)$, umbilical arterial $\mathrm{pH}<7.2(23.7 \%, 279 / 1179$ vs $9.1 \%, 321 / 3527)$, neonatal resuscitation $(59.9 \%, 706 / 1179$ vs $51.8 \%$, $1828 / 3527)$, neonatal intensive care unit admission $(9.8 \%, 116 / 1179$ vs $2.5 \%, 87 / 3527)$ and seizures $(0.8 \%, 10 / 1179$ vs $0.3 \%, 9 / 3527)$, respectively.

Conclusions: These results demonstrate significantly poorer outcomes associated with term category $1 \mathrm{CS}$ compared with non-category 1 emergency CS.

\section{INTRODUCTION}

Perinatal outcomes following emergency caesarean section (CS) depend on the gestation that the CS is performed as well as the indication for the emergent delivery. What is

\section{Strengths and limitations of this study}

- Large contemporary cohort from a tertiary centre.

- Clearly defined neonatal outcomes following a category 1 caesarean section at term.

- Results may help in identifying maternal/fetal risk factors that predispose to intrapartum compromise.

- Retrospective study.

- Not all neonatal outcomes were captured.

- Only relevant to term appropriately grown babies.

clear is that women who undergo CS not surprisingly have higher rates of complications including infection and pain, repeat admission, delayed mother-child bonding, difficulty in breast feeding as well as complications in future pregnancies. ${ }^{1-6}$ In addition to maternal complications, there are significant neonatal consequences as well, including increased rates of admission to hospital, respiratory and neurological morbidity and mortality. ${ }^{7-10}$ In the UK, almost two-thirds of CS performed were emergency cases. ${ }^{11}$ In high-income settings, electronic fetal monitoring, prenatal and intrapartum ultrasound, obstetric facilities with availability for immediate operative delivery and advanced neonatal care all help reduce the risk of an intrapartum event resulting in adverse neonatal outcomes. These resources are largely unavailable in low-income countries.

Classification of the degree of urgency of $\mathrm{CS}$ is generally based on one of four categories: ${ }^{12}$ category 1 -immediate threat to life (maternal or fetal); category 2-maternal or fetal compromise that is not immediately lifethreatening; category 3-needing early delivery but no maternal or fetal compromise or category 4-delivery at the convenience of the patient or obstetric team. Professional bodies such as the American College of Obstetrics and Gynaecology, National Institute of Clinical Excellence in the UK and the Royal Australian and New Zealand 
College of Obstetricians and Gynaecologists all have broadly similar recommendations in that the decision-to-delivery interval for category 1 CS should be no longer than $30 \mathrm{~min}$.

Category $1 \mathrm{CS}$, particularly in the setting of fetal compromise, carry significant risks with higher rates of complications. ${ }^{13} 14$ While the mode of delivery may not influence outcomes at very preterm gestations because of the confounding influence of gestation, this is not the case for term deliveries. The aim of this study therefore was to investigate neonatal outcomes following a category $1 \mathrm{CS}$ at term and to ascertain obstetric factors that might influence these outcomes.

\section{METHODS}

This was a retrospective observational study of category 1 CS for term (37-42 weeks) singleton deliveries at the Mater Mothers' Hospital in Brisbane, Australia between May 2007 and June 2014. The Mater Mothers' Hospital is the largest maternity hospital in Australia and delivers approximately one in six of all babies born in Queensland (approximately 60000 births annually). A category $1 \mathrm{CS}$ was defined as a CS that required a decision-to-delivery time interval of not more than $30 \mathrm{~min}$ for any indication that posed an immediate threat to the life of the woman or her fetus.

Maternal demographic data and perinatal outcome data were collected from the hospital's maternity database and cross-referenced with the maternal and fetal medicine and neonatal databases to ensure robust data ascertainment for maternal demographics, gestation and mode of delivery and neonatal outcomes. Exclusion criteria included privately insured patients, multiple pregnancy, known fetal demise at any gestation but prior to labour, known lethal abnormality or confirmed aneuploidy. Gestational age was calculated from either the last menstrual period or by the earliest ultrasound examination.

Demographic information collected included body mass index (BMI), maternal age, mode of conception (spontaneous vs assisted), maternal medical conditions (hypertension/preeclampsia, thyroid disease and diabetes mellitus) and smoking history. Perinatal outcome data included low Apgar scores defined as $<7$ at $5 \mathrm{~min}$, need for neonatal resuscitation or neonatal complications as defined by the attending neonatologist (eg, respiratory distress), neonatal intensive care unit (NICU) admission, neonatal seizures and death prior to discharge. Neonatal death was defined as death in the first 28 days following birth. This study did not investigate maternal outcomes or complications relevant to the mode of delivery. Data on the indication for CS (nonreassuring fetal status, failure to progress in labour, malpresentation, failed instrumental delivery, antepartum haemorrhage $(\mathrm{APH}) /$ placenta praevia, maternal disease, and cord prolapse, repeat CS in labour and other) and incidence of postpartum haemorrhage were also collected. The fetal heart rate patterns, defined as non-reassuring fetal status, were classified as either suspicious or pathological heart rate patterns as defined by the National Institute of Clinical Excellence. ${ }^{15}$ It was not possible to discriminate between women admitted in spontaneous labour and those being induced.

Normally distributed variables were compared using a two sample t test or analysis of variance if there were three or more groups. Non-normally distributed variables were compared using a Wilcoxon rank-sum test for two groups or the Kruskal-Wallis test if there were three or more groups. Frequencies were compared using a $\chi^{2}$ test. The proportion of infants in each category of indication for CS was compared using a $\mathrm{z}$ test for two proportions. The level of significance was 0.05. Summary statistics are reported as mean (SD) or median (IQR) as appropriate. Statistical analysis for this study was performed using the Stata statistics program (http://www. stata.org).

\section{RESULTS}

Over the study period, a total of 30719 women fulfilling the inclusion criteria were included in the study. The overall emergency CS rate for term singleton pregnancies was $15.3 \%(4706 / 30719)$. Of these, 1179 women $(3.8 \%)$ required a category 1 CS for delivery and 3527 women $(11.5 \%)$ had emergency CS for other indications. Maternal demographics and indications for the CS are presented in table 1 . Neonatal outcomes are shown in table 2. The median age for both cohorts was 30 years (IQR 26-34). Caucasian ethnicity was most common for both cohorts, accounting for $52.7 \%(621 / 1158)$ of the category 1 cohort and $52.4 \%(1847 / 3527)$ of the noncategory 1 cohort,respectively. Country of birth, defined as either born in Australia, or born outside of Australia, was not significantly different between the two cohorts, with $49.4 \%$ of women $(582 / 1158)$ born in Australia and $50.6 \%(597 / 1158)$ born outside of Australia for the category 1 cohort; and $50.8 \%(1792 / 3527)$ born in Australia and $49.2 \%(1735 / 3527)$ born outside of Australia for the non-category 1 cohort.

Women in the category 1 CS cohort had lower BMIs (23.4, IQR 20.6-27.2) compared with the non-category 1 cohort (23.7, IQR 20.9-28; $\mathrm{p}=0.007)$. There was no difference in the rates of maternal medical conditions between the two groups. Within the category 1 cohort, the most common indication for delivery was nonreassuring fetal status $(65.9 \%, 777 / 1179)$, followed by malpresentation $(10.1 \%, 119 / 1158)$, and failed instrumental $(8.2 \%, 97 / 1158)$. Within the non-category 1 cohort, the most common indication for emergency CS was failure to progress $(46.5 \%, 1641 / 3527)$, followed by non-reassuring fetal status $(19 \%, 671 / 3527)$ and malpresentation $(12.4 \%, 437 / 3527$; table 1$)$.

Median gestational age at birth was similar for both cohorts (40 weeks); however, the slight difference in distribution (IQR 39-41 for category 1 CS compared with 
Table 1 Maternal demographics-term category $1 \mathrm{CS}$, and term non-category $1 \mathrm{CS}$

\begin{tabular}{|c|c|c|c|}
\hline & Term category 1 CS $(n=1179)$ & $\begin{array}{l}\text { Other term emergency CS } \\
\text { (exclusion category } 1 \mathrm{CS}) \\
(\mathrm{n}=3527)\end{array}$ & p Value \\
\hline Age* $^{*}$ & $30(26-34)$ & $30(26-34)$ & 0.33 \\
\hline $\mathrm{BMI}^{*}$ & $23.4(20.6-27.2)$ & 23.7 (20.9-28) & 0.007 \\
\hline \multicolumn{4}{|l|}{ Ethnicity } \\
\hline Caucasian & $621(52.7)$ & $1847(52.4)$ & \\
\hline ATSI & $38(3.2)$ & $92(2.6)$ & 0.30 \\
\hline Asian & $287(24.3)$ & $842(23.9)$ & 0.80 \\
\hline Other/not listed & 233 (19.8) & 746 (21.2) & 0.27 \\
\hline Born in Australia & $582(49.4)$ & $1792(50.8)$ & \\
\hline Born outside of Australia & $597(50.6)$ & 1735 (49.2) & 0.4 \\
\hline \multicolumn{4}{|l|}{ Medical history } \\
\hline \multicolumn{4}{|l|}{ Hypertension } \\
\hline Chronic hypertension & $11(0.9)$ & 45 (1.3) & 0.44 \\
\hline Gestational hypertension & $14(1.2)$ & $80(2.3)$ & 0.02 \\
\hline Preeclampsia & $14(1.2)$ & 46 (1.3) & 0.65 \\
\hline No hypertension & $1140(96.7)$ & 3356 (95.2) & \\
\hline \multicolumn{4}{|l|}{ Diabetes mellitus } \\
\hline No known diabetes & $1145(97.1)$ & $3411(96.7)$ & \\
\hline Gestational diabetes & $6(0.5)$ & $13(0.4)$ & 0.59 \\
\hline Type 1 diabetes mellitus & $4(0.3)$ & $10(0.3)$ & 0.76 \\
\hline Type 2 diabetes mellitus & $2(0.2)$ & $10(0.3)$ & 0.75 \\
\hline Diabetes mellitus_-indeterminate type & $22(1.9)$ & $82(2.3)$ & 0.36 \\
\hline Thyroid disease & $5(0.4)$ & $20(0.6)$ & 0.82 \\
\hline \multicolumn{4}{|l|}{ CS indication } \\
\hline Non-reassuring fetal status & $777(65.9)$ & $671(19)$ & $<0.0001$ \\
\hline Failure to progress & $119(10.1)$ & $1641(46.5)$ & $<0.0001$ \\
\hline Malpresentation & $68(5.8)$ & 437 (12.4) & 0.11 \\
\hline Failed instrumental & 97 (8.2) & $56(1.6)$ & 0.09 \\
\hline APH/placenta praevia & $40(3.4)$ & $31(0.9)$ & 0.49 \\
\hline Maternal disease & $16(1.4)$ & $70(2)$ & 0.87 \\
\hline Cord prolapse/presentation & $25(2.1)$ & $7(0.2)$ & 0.73 \\
\hline Repeat CS & $14(1.2)$ & $424(12)$ & 0.21 \\
\hline Other & $23(2)$ & $190(5.4)$ & 0.48 \\
\hline PPH (Number (\%)) & $22(1.9)$ & $48(1.4)$ & 0.213 \\
\hline
\end{tabular}

Table 2 Perinatal outcomes-term category $1 \mathrm{CS}$, and term non-category $1 \mathrm{CS}$

\begin{tabular}{|c|c|c|c|}
\hline & $\begin{array}{l}\text { Term category } 1 \text { CS } \\
(n=1179)\end{array}$ & $\begin{array}{l}\text { Other term emergency CS } \\
\text { (exclusion category } 1 \mathrm{CS} \text { ) } \\
(\mathrm{n}=3527)\end{array}$ & p Value \\
\hline Gestation at delivery* & $40(40-41)$ & $40(38-41)$ & $<0.0001$ \\
\hline Birth weight $(g)^{*}$ & 3420 (3095-3770) & 3550 (3190-3920) & $<0.0001$ \\
\hline Apgar $<7$ at $1 \mathrm{~min}$ & $241(20.4)$ & $377(10.7)$ & $<0.0001$ \\
\hline Apgar $<7$ at $5 \mathrm{~min}$ & $68(5.8)$ & $67(1.9)$ & $<0.0001$ \\
\hline Umbilical arterial $\mathrm{pH}<7.2$ & $279(23.7)$ & $321(9.1)$ & $<0.0001$ \\
\hline Respiratory distress & $193(16.4)$ & $266(7.5)$ & $<0.0001$ \\
\hline Neonatal resuscitation & 706 (59.9) & $1828(51.8)$ & $<0.0001$ \\
\hline NICU admission & $116(9.8)$ & $87(2.5)$ & $<0.0001$ \\
\hline Seizure & $10(0.8)$ & $9(0.3)$ & 0.013 \\
\hline
\end{tabular}

Data presented as $\mathrm{N}$ (percentage) unless otherwise specified.

*Data presented as median (IQR).

$\mathrm{CS}$, caesarean section; NICU, neonatal intensive care unit. 
IQR 38-41 for non-category $1 \mathrm{CS}$ ) resulted in a statistically significant difference, most likely due to the large numbers in each group. The median birth weight for babies delivered by a category $1 \mathrm{CS}$ was $3420 \mathrm{~g}$ (IQR 3095-3770) compared with $3550 \mathrm{~g}$ (IQR 3190-3920) for the non-category 1 group. Perinatal outcomes, including Apgar scores at 1 and $5 \mathrm{~min}$, umbilical arterial $\mathrm{pH}$, respiratory distress, need for resuscitation and NICU admission, were significantly worse in the category 1 cohort (table 2). There were no intrapartum or neonatal deaths in either the category 1 or non-category 1 cohorts.

\section{DISCUSSION}

The results from this study demonstrate the significantly worse perinatal outcomes for women who undergo a category $1 \mathrm{CS}$ at term. Although the overall rates of emergency CS for non-reassuring fetal status in the entire cohort was relatively low $(4.7 \%, 1448 / 30719)$, it is in this category of cases that the most adverse neonatal outcomes occurred.

The predominant indication for delivery in this cohort was non-reassuring fetal status which occurred in almost two-thirds of all cases compared to $19 \%$ for non-category 1 cases. Not surprisingly, failed instrumental delivery, cord presentation/prolapse and $\mathrm{APH} /$ placenta praevia also featured more commonly in the category 1 group as all these indications have potentially significant fetal or maternal consequences if delivery is not achieved rapidly. Our study did not have any cases of intrapartum demise or neonatal death in either CS cohort. This may reflect the standard of obstetric, anaesthetic and neonatal care in a major metropolitan teaching hospital with all the relevant facilities and expertise readily available. Although babies that are growth restricted are at increased risk of intrapartum complications, ${ }^{16}$ we did not find such an association in our study. Despite being statistically significant, the median birth weight discordance between category 1 and non-category 1 emergency CS (3420 g vs $3550 \mathrm{~g}$ ) was small. This is unlikely to be of any clinical significance and does not suggest obvious significant suboptimal growth in either cohort. Although our study specifically looked at term fetuses and demonstrated a difference in neonatal outcomes, older studies did not show a similar difference in a term cohort when preterm newborns were excluded from analysis.

To improve care in labour, the American College of Obstetrics and Gynaecology, ${ }^{17}$ the Royal Australian and New Zealand College of Obstetricians and Gynaecologists ${ }^{18}$ and the National Institute of Clinical Excellence ${ }^{15}$ in the UK as well as professional bodies in other countries have all published guidelines for intrapartum fetal monitoring as well as recommendations for regular training for obstetric healthcare providers. There is some evidence that such guidelines and training programmes have resulted in a reduction in the incidence of serious complications such as hypoxic ischaemic encephalopathy. ${ }^{19}$ Nevertheless, the ideal decision-to-incision interval remains controversial, particularly because of the lack of good evidence of adverse neonatal outcomes, despite many institutions failing to achieve the universal 30 min standard. ${ }^{20}$

Although acute intrapartum events severe enough to cause profound hypoxia or death in the fetus are fortunately relatively rare, suboptimal intrapartum care or failure to recognise signs of developing fetal compromise is not. In the USA, it is estimated that the complication rate during labour and delivery is $2.8 \%$, with $27.7 \%$ of those attributed to negligence and nearly $10 \%$ of adverse events being associated with serious disability. ${ }^{21}$ Furthermore, current available evidence from both clinical and neuroradiological studies suggests that most cases of neonatal encephalopathy are of peripartum origin. $^{22-26}$

Although it is likely that better training and adherence to intrapartum monitoring guidelines will improve outcomes, it is clearly preferable to identify fetuses at risk of intrapartum compromise before labour. There is emerging evidence that in term, appropriately grown babies, the cerebroumbilical ratio and umbilical venous flow rate $^{2728}$ may be helpful in stratifying pregnancies at risk of intrapartum compromise and of requiring emergency CS for delivery. The risks of birth are considerable and it has recently been demonstrated that the likelihood of death on the day of birth exceeds that of any other day until early in the tenth decade of life. ${ }^{29}$

The ability to identify women with pregnancies that are apparently low risk at first glance but who are actually at high risk of intrapartum fetal compromise, may allow for these women to be offered alternative delivery options or enhanced monitoring in labour with recourse to early CS if any concerns developed intrapartum. This approach would have the benefit of obviating the risks associated with labour and reduce neonatal complications associated with intrapartum hypoxia. Clearly, there would be a trade-off in terms of maternal operative risks; however, it is likely that the judicious use of appropriate obstetric intervention will result in an immediate decrease in intrapartum and neonatal mortality rates which are currently disproportionately over-represented in low-income and middle-income countries. ${ }^{30}$

In a thought-provoking hypothetical scenario, Hankins et $a l^{31}$ demonstrated that if a near universal CS for all women at 39 weeks was performed in the USA, this would theoretically prevent 6000 fetal deaths annually and would reduce by $83 \%$ the number of newborns with moderate or severe neonatal hypoxic encephalopathy. While this is clearly not a practical solution, it is not unreasonable to suppose that such an approach for a small segment of women who are at high risk of intrapartum fetal compromise may be one option to reduce neonatal morbidity and mortality. Conversely, in healthcare settings with only limited resources for intrapartum monitoring, a more liberal use of CS to deliver babies that are at high risk of intrapartum compromise will certainly increase the overall rates of operative delivery. 
This may not be such a bad thing, as in these countries operative delivery rates are probably too low and a slight increase in these rates could translate into tangible improvements in perinatal outcomes.

There has been much debate regarding the optimum CS rate that an institution or nation should aspire to with the WHO recommending that CS rates should not exceed $15 \%$. Nevertheless, CS rates worldwide are steadily increasing with rates in the USA now $>30 \%{ }^{832} 33$ with similar rises in Australia. ${ }^{34}$ Regardless of the debate of the optimal CS rate, as category $1 \mathrm{CS}$ in high-income countries account for only $<7 \%$ of all CS performed, in our view if reduction of the CS rate is the desired aim, then this is more likely to be achieved by improved management of labour and a reduction in the rates of elective CS for 'soft' indications.

Although a recent study ${ }^{35}$ suggested that NICU admission was a poor outcome measure for neonatal morbidity when comparing different birth settings, this is not particularly relevant to our study as our study was conducted in a single tertiary centre. Furthermore, we used a composite of various other measures of neonatal wellbeing at birth to enhance the rigour of outcome measure.

The results of this study demonstrate the need for careful consideration of antenatal and intrapartum risk factors that may lead to a category $1 \mathrm{CS}$. It may be possible in the future to reduce the rates of emergency intrapartum CS for non-reassuring fetal status by prenatally identifying babies at risk of intrapartum compromise. Refinements of such techniques as well as early recognition of antenatal and intrapartum risk factors are important in order to optimise maternal and neonatal outcomes.

Contributors SK and RMG were responsible for the study design. LG, RMG and SK were responsible for data analysis and the writing of the manuscript. All the authors approved the final draft.

Funding This research received no specific grant from any funding agency in the public, commercial or not-for-profit sectors.

Competing interests None declared.

Ethics approval Ethical and governance approvals for this study were granted by the Mater Human Research Ethics and Governance Committees (HREC/14/ MHS/63 and RG19 HREC/14/MHS/61), respectively.

Provenance and peer review Not commissioned; externally peer reviewed.

Data sharing statement No additional data are available.

Open Access This is an Open Access article distributed in accordance with the Creative Commons Attribution Non Commercial (CC BY-NC 4.0) license, which permits others to distribute, remix, adapt, build upon this work noncommercially, and license their derivative works on different terms, provided the original work is properly cited and the use is non-commercial. See: http:// creativecommons.org/licenses/by-nc/4.0/

\section{REFERENCES}

1. Lydon-Rochelle M, Holt VL, Martin DP, et al. Association between method of delivery and maternal rehospitalization. JAMA 2000;283:2411-16.

2. Prior E, Santhakumaran S, Gale C, et al. Breastfeeding after caesarean delivery: a systematic review and meta-analysis of world literature. Am J Clin Nutr 2012; 95:1113-35

3. Silver RM, Landon MB, Rouse DJ, et al. Maternal morbidity associated with multiple repeat caesarean deliveries. Obstet Gynecol 2006;107:1226-32.

4. Azam S, Khanam A, Tirlapur S, et al. Planned caesarean section or trial of vaginal delivery? A meta-analysis. Curr Opin Obstet Gynecol 2014;26:461-8.

5. Visser GH. Women are designed to deliver vaginally and not by caesarean section: an obstetrician's view. Neonatology 2014;107:8-13.

6. DiMatteo MR, Morton SC, Lepper HS, et al. Caesarean childbirth and psychosocial outcomes: a meta-analysis. Health Psychol 1996;15:303-14.

7. Silver RM. Implications of the first caesarean: perinatal and future reproductive health and subsequent caesareans, placentation issues, uterine rupture risk, morbidity, and mortality. Semin Perinatol 2012;36:315-23.

8. Menacker F, Hamilton BE. Recent trends in caesarean delivery in the United States. NCHS Data Brief March 2010;(35):1-8.

9. De Luca R, Boulvain M, Irion $\mathrm{O}$, et al. Incidence of early neonatal mortality and morbidity after late-preterm and term caesarean delivery. Pediatrics 2009;123:e1064-71.

10. Essex HN, Green J, Baston $\mathrm{H}$, et al. Which women are at an increased risk of a caesarean section or an instrumental vaginal birth in the UK: an exploration within the Millennium Cohort Study. BJOG 2013;120:732-42; discussion 42-3.

11. Thomas J, Paranjothy S. National Sentinel Caesarean Section Audit Report: Clinical Effectiveness Support Unit. RCOG Press 2001.

12. Lucas DN, Yentis SM, Kinsella SM, et al. Urgency of caesarean section: a new classification. J $R$ Soc Med 2000;93:346-50.

13. Zhang Q, Dunn C, Sia J, et al. Category one caesarean section: a team-based approach. Trends Anaes Crit Care 2014 (4):97-101.

14. Pallasmaa N, Ekblad U, Aitokallio-Tallberg A, et al. Caesarean delivery in Finland: maternal complications and obstetric risk factors. Acta Obstet Gynecol Scand 2010;89:896-902.

15. NICE. Intrapartum care: care of healthy women and their babies during childbirth, 2007. http://www.nice.org.uk/guidance/cg55

16. Gilbert WM, Danielsen B. Pregnancy outcomes associated with intrauterine growth restriction. Am J Obstet Gynecol 2003;188:1596-9; discussion 99-601.

17. American College of Obstetricians and Gynecologists. ACOG. Practice Bulletin No. 106-Intrapartum fetal heart rate monitoring: nomenclature, interpretation and general management principles. Obstet Gynecol 2009;114:192-202.

18. RANZCOG. Intrapartum Fetal Surveillance. Clinical Guideline. 3rd edn 2014. https://www.ranzcog.edu.au/intrapartum-fetal-surveillanceclinical-guidelines.html

19. Byford S, Weaver E, Anstey C. Has the incidence of hypoxic ischaemic encephalopathy in Queensland been reduced with improved education in fetal surveillance monitoring? Aust $N Z J$ Obstet Gynaecol 2014;54:348-53.

20. Tolcher MC, Johnson RL, El-Nashar SA, et al. Decision-to-incision time and neonatal outcomes: a systematic review and meta-analysis. Obstet Gynecol 2014;123:536-48.

21. Schifrin BS, Cohen WR. The effect of malpractice claims on the use of caesarean section. Best Pract Res Clin Obstet Gynaecol 2013;27:269-83.

22. Berglund S, Norman M. Neonatal resuscitation assessment: documentation and early paging must be improved! Arch Dis Child Fetal Neonatal Ed 2012;97:F204-8.

23. Cowan F, Rutherford M, Groenendaal F, et al. Origin and timing of brain lesions in term infants with neonatal encephalopathy. Lancet 2003;361:736-42

24. Murray DM, O'Riordan MN, Horgan R, et al. Fetal heart rate patterns in neonatal hypoxic-ischemic encephalopathy: relationship with early cerebral activity and neurodevelopmental outcome. Am J Perinatol 2009;26:605-12.

25. Jonsson M, Agren J, Norden-Lindeberg S, et al. Neonata encephalopathy and the association to asphyxia in labor. $A m \mathrm{~J}$ Obstet Gynecol 2014;211:667.e1-8.

26. Berglund S, Grunewald C, Pettersson $\mathrm{H}$, et al. Severe asphyxia due to delivery-related malpractice in Sweden 1990-2005. BJOG 2008;115:316-23.

27. Prior T, Mullins $\mathrm{E}$, Bennett $\mathrm{P}$, et al. Prediction of intrapartum fetal compromise using the cerebroumbilical ratio: a prospective observational study. Am J Obstet Gynecol 2013; 208:124 e1-6. 
28. Prior $T$, Mullins $E$, Bennett $P$, et al. Umbilical venous flow rate in term fetuses: can variations in flow predict intrapartum compromise? Am J Obstet Gynecol 2014;210:61 e1-8.

29. Walker KF, Cohen AL, Walker SH, et al. The dangers of the day of birth. BJOG 2014;121:714-18.

30. Lawn JE, Blencowe H, Pattinson R, et al. Stillbirths: Where? When? Why? How to make the data count? Lancet 2011;377:1448-63.

31. Hankins GD, Clark SM, Munn MB. Caesarean section on request at 39 weeks: impact on shoulder dystocia, fetal trauma, neonatal encephalopathy, and intrauterine fetal demise. Semin Perinatol 2006;30:276-87.

32. Stavrou EP, Ford JB, Shand AW, et al. Epidemiology and trends for caesarean section births in New South Wales,
Australia: a population-based study. BMC Pregnancy Childbirth 2011;11:8.

33. Osterman MJ, Martin JA. Changes in caesarean delivery rates by gestational age: United States, 1996-2011. NCHS Data Brief June 2013;(124):1-8.

34. Li Z, Zeki R, Hilder L, et al. Australia's mothers and babies 2010 perinatal statistics series No. 27. Category No. PER 57. AlHW National Perinatal Epidemiology and Statistics Unit, 2012.

35. Wiegerinck MM, Danhof NA, Van Kaam AH, et al. The validity of the variable "NICU admission" as an outcome measure for neonatal morbidity: a retrospective study. Acta Obstet Gynecol Scand 2014:93:603-9. 